Wilfrid Laurier University

Scholars Commons @ Laurier

Psychology Faculty Publications

Psychology

2016

\title{
Challenges Facing East Asian Immigrant Children in Sexual Abuse Cases
}

Kim Roberts

Wilfrid Laurier University, kroberts@wlu.ca

Hongyuan Qi

Wilfrid Laurier University, qixx8480@mylaurier.ca

Huan Zhang

Wilfrid Laurier University, zhan8620@mylaurier.ca

Follow this and additional works at: https://scholars.wlu.ca/psyc_faculty

Part of the Psychiatry and Psychology Commons

\section{Recommended Citation}

Roberts, K. P., Qi, H., \& Zhang, H. H. (2016). Challenges facing east asian immigrant children in sexual abuse cases. Canadian Psychology, 57(4), 300-307. doi:http://dx.doi.org/10.1037/cap0000066

This Article is brought to you for free and open access by the Psychology at Scholars Commons @ Laurier. It has been accepted for inclusion in Psychology Faculty Publications by an authorized administrator of Scholars Commons@ @aurier. For more information, please contact scholarscommons@wlu.ca. 
Challenges Facing East Asian Immigrant Children in Sexual Abuse Cases

\author{
Kim P Roberts ${ }^{1}$
}

\author{
Hongyuan Qi Huan Huan Zhang
}

Wilfrid Laurier University

Corresponding Author: Kim P Roberts, PhD, Department of Psychology, Wilfrid Laurier University, 75 University Avenue West, Waterloo, Ontario, Canada. kroberts@ wlu.ca Tel: +1 5198840710 extension 3225 


\section{Abstract}

Immigrants from East Asia make up 14.21\% of the total number of immigrants in

Canada. These families face many challenges as they acculturate to North America but, sadly, some of these children may be at risk for sexual abuse. In this position paper, we outline the ways in which East Asian children are at a particular disadvantage when considering prosecution of those who perpetrate abuse compared to Western non-immigrant children. We focus specifically on three areas of concern: 1) Cultural differences that can shape children's memory recall; 2) Cultural differences that can impact the path of disclosure of sexual abuse; and, 3) Language differences which reduce the chances that perpetrators will be prosecuted for sexual abuse. The consequences for East Asian immigrant youth who allege (or are suspected) that they are victims of abuse are serious. East Asian children face an uphill battle to see justice in sexual abuse cases. Thus, a significant portion of immigrant children will not see their abusers punished and, worse, the knowledge that prosecution is unlikely may make East Asian immigrant children vulnerable. 


\begin{abstract}
Les immigrants de l'Asie de l'Est représentent 14,21\% du nombre total d'immigrants au Canada. Ces familles font face à de nombreux défis dans leur processus d'acculturation en Amérique du Nord. Malheureusement, certains de ces enfants sont à risque d'être victimes d'abus sexuel. Dans cet article où nous prenons position, nous décrivons en quoi les enfants de l'Asie de l'Est sont particulièrement désavantagés dans le cadre des poursuites contre les personnes qui commettent des abus, en comparaison aux enfants occidentaux non immigrants. Nous portons une attention spécifique à deux enjeux: 1) les différences culturelles qui peuvent avoir un impact sur la divulgation des abus sexuels; et 2) les différences linguistiques qui réduisent les probabilités que les auteurs des abus soient poursuivis. Les conséquences sont graves pour les jeunes immigrants d'Asie de l'Est qui font des allégations d'abus (ou qu'on suspecte en être victimes). La bataille à laquelle ils sont confrontés est ardue pour obtenir justice dans les cas d'abus sexuels. Ainsi, une proportion importante des enfants immigrants ne verront pas leurs agresseurs punis. Pire encore, le fait que la poursuite est peu probable peut contribuer à rendre vulnérables les enfants immigrants d'Asie de l'Est.
\end{abstract}




\section{Challenges Facing East Asian Immigrant Children in Sexual Abuse Cases}

A substantial portion of immigrants to Canada comes from East Asia (e.g., Mainland

China, Taiwan, Hong Kong and Korea). In this paper, we discuss how culture shapes the way that children recall autobiographical events, how language differences can affect prosecutions of child sexual abuse, and why cultural differences (between East Asia and North America) may affect the likelihood that children disclose abuse. These three factors closely interplay with each other, which can lead child abuse victims who are from East Asian cultures to be underrepresented and disadvantaged in the Canadian legal system.

In this position paper, we discuss the severe consequences that may face East Asian immigrant families when their children try to disclose alleged sexual abuse. In particular, we will refer to Mandarin Chinese speakers. We will first discuss the role of children in investigations of abuse in Canada, and then outline some cultural differences between Euro-Canadian and Asian cultures. We then present our argument about how cultural and language differences may impact the investigation and prosecution of abuse.

Child sexual abuse investigations can take place in two ways: Children could directly voice the allegations (known as 'disclosure') or a concerned adult might suspect abuse and report it to authorities. In both Canada and the United States, there is mandatory reporting of abuse (i.e., adults must report suspected abuse to the authorities or risk being 'accessories' to the abuse). A common sequence of events after a disclosure/suspicion of abuse is for the relevant child welfare and legal authorities to proceed with an investigation to determine, first, if the child is in imminent danger, and second whether there is information of sufficient quality to proceed with an investigation (Brubacher, Bala, Roberts, \& Price, 2016). Although there are sometimes witnesses who can give first-hand accounts, Sexual abuse often takes place in private and so the 
only testimony can come from the child and/or the perpetrator. Suspected perpetrators commonly deny the abuse unless there is a credible, quality statement from the alleged victim (Pipe, Orbach, Lamb, Abbott, \& Stewart, 2013). Thus, what children say in investigative (forensic) interviews is critical to decisions about whether to prosecute or not.

It is our argument that East Asian immigrant children are particularly disadvantaged and, potentially, at-risk, compared to Westernized children. As illustrated in Figure 1, we focus specifically on three areas of concern: 1) Cultural differences that can shape children's memory recall; 2) Cultural differences that can impact the path of disclosure of sexual abuse; and, 3) Language differences which reduce the chances that perpetrators will be prosecuted for sexual abuse. Before discussing these cultural differences, we will outline the role of memory in a forensic interview given the importance of children's role as victim-witnesses. This provides the reader with a clear idea of what is involved in Canadian investigations of child abuse.

\section{Children's Memory and the Forensic Interview}

Good forensic interviewers allow children to freely recall what happened to them. This means that children are free to choose what information they report. There are no hints or suggestions at this stage as to what sort of details are needed. When we recall, one memory reminds us of another memory and so on. In more visual terms, picture a web of neuronal pathways each connected to another. Each pathway produces a memory and links to the next piece of information. Thus, we can recall many details about an experienced event.

Recalling memories requires a larger cognitive load than recognizing pieces of information. An interviewer who asks "Was your mum there?" is asking the child to recognize if mum was present. Although recognition is easier than recall, it is not a forensically valid technique in child sexual abuse interviews. By describing a piece of information, the interviewer 
is suggesting information which may or may not be true. A very large body of laboratory studies have shown that recalled memories are more descriptive and accurate than simply recognizing information (see Lamb, Orbach, Hershkowitz, Esplin, \& Horowitz, 2007 for a review). Thus, while recall is the preferred method to elicit children's allegations of sexual abuse, it is still a task that children can find difficult unless they have been trained to recall events (see Roberts, Brubacher, Price, \& Powell, 2011).

While memories decay over time making events harder and harder to recall in detail, various factors increase the likelihood of accurately recalling a distant event. Each time we are reminded about the event, the event memory becomes stronger and is more resistant to decay than events we rarely think about (Roberts \& Powell, 2007). This can be seen in practical ways such as the finding that learned information is retained for longer when the learning is spaced out over several sessions, rather than crammed (Rischke, Roberts, \& Price, 2011). Or the compulsive need to repeat a license plate over and over to keep it in memory. Reminders can also take other forms, such as talking or thinking about the event, seeing a similar situation on television, reading about others' experiences that are similar to yours, or actually experiencing the same event again. The sad fact is that at least half of the children who allege sexual abuse have been abused on more than one occasion (Trocmé et al., 2010). The individual incidents often share similar characteristics (e.g., "He waits until mom leaves and then does it", Brubacher, Powell, \& Roberts, 2014). It is clear after decades of research that children's memories of events that have been repeated is quite different to memories of events that happen just one time.

In North American legal systems, it is common for interviewers to try to glean information about separate incidents of abuse. For example, prosecution is easier if a child describes 'the time at Dad's house' than if a more generic description is given (e.g., 'It happens 
at Dad's house'; Brubacher et al., 2014). There are several legal reasons for the need to particularize separate incidents such as being able to lay specific charges and determine sentencing. Our previous research (e.g., Roberts \& Powell, 2006), case law (e.g., $R$ v. $B[G]$, 1990), surveys of interviewers (e.g., Roberts \& Cameron, 2015), and our discussions with investigators indicate that child witnesses find it difficult to connect 'particulars' or details with the exact individual acts or occurrences. Typically, children are confused between occurrences, even though much of what they recall is accurate (Powell \& Thomson, 1996). Therefore, particularizing is a difficult task for children. Although there have been some promising interview techniques that reduce the confusions between occurrences (e.g., Brubacher, Roberts, \& Powell, 2012; Thierry \& Spence, 2002), there is much more research to be done in this area. In contrast to remembering individual occurrences, children's memories for the gist of events are easily retrieved, accurate, and include relevant forensic details such as the timing and sequence of actions in the event. When we experience similar events repeatedly, our brains form a mental structure called an event 'script' (Hudson, Fivush, \& Kuebli, 1992). A script includes all of the information that usually happens whenever an event is experienced over and over. Even young children can accurately retrieve a script for events with which they are very familiar such as their daycare routine (Hudson \& Nelson, 1986). The significance of recalling a script versus an individual occurrence will become apparent in the following sections.

In sum, children can have remarkably good memories (e.g., scripts) but difficulty when describing individual incidents of abuse. The companion of recalling memories of sexual abuse is describing them verbally to detectives. A child may remember the abuse but not verbally describe it, either because they do not want to disclose or are having difficulties putting their memories into words. Figure 1 represents the unique properties of East Asian children's 
memories and the mechanisms through which we believe East Asian immigrant children who have been abused are at a disadvantage. We will explain this figure as we discuss how East Asian's 1) Cultural norms, and 2) Language, are not supported in Western legal systems.

\section{Culture Differences That Can Impact Memory}

Confucianism has generated a profound impact on the underlying ideology of East Asian culture. Confucianism aimed to promote humanity (ren), righteousness (yi) and virtue (de) to achieve social stability, prosperity, and harmony. Therefore, in accord with the Confucian philosophy, harmony is the highest and the most valuable virtue that individuals should possess as it is essential in maintaining peace in the society and family (Yao, 2000). Confucius had approximately three thousand disciples disseminating the Confucian doctrines (Yao, 2000). For example, Korea, Japan, and Taiwan are greatly influenced by the Confucian philosophy in their value systems and moral principles (Ma \& Smith, 1992; Yao, 2000). Thus, given the emphasis of interrelatedness and group solidarity in Confucian ideology and its prevailing influences, the majority of East Asians foster collectivist values. In comparison to the collectivism in East Asia, North Americans endorse individualism, in which individuals are encouraged to be independent of others and pursue the distinctiveness of the self (Markus \& Kiytama, 1991).

The ideological differences between East Asians and North Americans have given rise to the cultural variations in individuals' self-construal, which is defined as individuals' perception of the self in the cultural context (Markus and Kitayama, 1991). Self-construal exerts its influence on individuals' thoughts and behaviours through the construct system. According to Kelly (1991), the construct system can guide individuals to construe the surrounding environment. Specifically, each individual's construct system is composed of a set of conceptual elements that are shaped by the broad socio-cultural context. Such a system can channelize 
individuals' thinking to anticipate, analyze and react to life events in ways that are meaningful to them and are consistent with how they conceptualize themselves in the embedded environment (Kelly, 1991). Cultural individualism-collectivism is the major predictor of the dimensions of individuals' self-construal (Gudykunst et al., 1996). For example, due to the importance of interpersonal harmony and connectedness in the collectivistic culture (Yao, 2000), those who are raised in such an environment may tend to view themselves to be inextricably associated with others, such as in family units. As a result, collectivistic culture encourages individuals to conform to interdependent self-construal (i.e., relational self-construal and collective selfconstrual). In contrast, individuals who have been brought up in an individualistic culture may tend to perceive themselves as a unique self that is independent from others because of Western societies’ emphasis on autonomy and idiosyncrasy (Markus \& Kitayama, 1991; Wang \& Conway, 2004; Wang \& Leichtman, 2000). Therefore, individualistic culture promotes individuals to establish independent self-construal (i.e., individualistic self-construal and autonomous self-construal).

Specifically, cultural self-construal plays an important role in affecting the underlying mechanisms of how individuals perceive, construe, and store information within the brain (Markus \& Kiytama, 1991). In other words, individuals tend to conceptualize themselves in ways that conform to their cultural values, which will serve as a general guide that directs their overall memory processes. According to Wang and Ross (2005), "cultural self-construal serves as a filter for individuals' memories of their life experiences". Thus, the dimensions of self-construal can orientate individuals' attention to certain information, determine the extent to which they will engage in elaborative rehearsal of incoming information during memory retention, and influence the manner in which they recall an experienced event. For instance, events that 
facilitate social interactions may be more likely to be richly presented, retained, and retrieved by those who have an interdependent self; whereas information that reflects the uniqueness of the self may be more likely to be deeply processed, remembered, and recalled by those who have an independent self (Wang, 2001).

Moreover, recent research has shown that the content and style of parent-child narrative practices is also closely linked to how children remember the past (Wang, 2007; Wang \& Leichtman, 2000; Wang, Leichtman, \& Davies, 2000). Specifically, researchers have suggested that parents tend to emphasize specific cultural values when reminiscing with their children. In particular, given the emphasis on interpersonal relationships in Eastern cultures, Eastern mothers tend to promote a sense of social hierarchy and obedience to the authority figure (e.g., parents and teachers) in their conversations with children (Wang et al., 2000). However, Western mothers who are instilled with values of autonomy and individuality tend to promote strong emotional attachment with their children in their narratives. Further, the results from Wang's (2007) longitudinal study have shown that Asian mothers' narratives are more repetitive, goal directed, and other-oriented; in contrast, European mothers' narratives are more elaborative, relaxed, and child-oriented (Kulkofsky, Wang, \& Hou, 2010; Wang, 2006a, 2007). Generally speaking, culture can drive the focus of mothers' reminiscing, which may determine what information children will internalize as important, and which will be elaborately represented in the child's memory and highly accessible during recall. As a result, the style of maternal reminiscing is also an important factor that predicts how children remember the past ${ }^{1}$.

Due to the diverse construal of the self in the different cultural milieus and the distinctive maternal beliefs and reminiscing practices across races, North Americans differ significantly

\footnotetext{
${ }^{1}$ We are not advocating that fathers have little impact on children's language and memory development, but published research has so far mostly documented maternal reminiscing.
} 
from East Asians in their autobiographical remembering. Generally speaking, autobiographical episodes that focus on the unique moment of the self (e.g., winning a competition and being praised by others) can strengthen individual idiosyncrasy; therefore, an independent self will have a stronger memory trace of such episodes than an interdependent self. North Americans recall more elaborate details that are self-focused; whereas, East Asians retrieve more generic and routine-based information with an emphasis on social interactions (Wang, 2001, 2009; Wang \& Conway, 2004).

These culturally-induced patterns of recall shape children's memories too (Han, Leichtman \& Wang, 1998; Peterson, Wang \& Hou, 2009; Wang \& Leichtman, 2000; Wang et al., 2000). For example, Han et al. (1998) compared the level of specificity, the amount of temporal markers, and descriptive terms in school-aged children's memory recollections across three nations (America, China, Korea). The results revealed that American children's recollections included more information about specific events, personal attributes (e.g., emotions, feelings and opinions), temporal relationships, and descriptive terms than East Asian children's recollections.

In Wang and Leichtman's (2000) study, they investigated Chinese and American children's memories about a series of stories. In line with Han et al.'s findings (1998), Wang and Leichtman (2000) found that Chinese children were more likely to turn the perceived information into a story that places an emphasis on social connectedness, moral norms, and the obedience to authority figures. However, American children's recollections of the stories comprised more details associated with autonomy and the internal attributes of the characters. Overall, cross-cultural research on children's memory for both experienced life events and stories has indicated invariant cross-cultural differences (Han et al., 1998; Peterson et al., 2009). 
That is, East Asian children recall more generic information that is social-oriented; whereas

North American children retrieve more specific and individual-oriented memories (see Figure 1).

\section{Cultural Differences That Can Impact Disclosure of Sexual Abuse}

Compared to America, Canada has limited resources that provide data pertaining to the influence of ethno-cultural factor on the report rate of Canadian children's sexual abuse incidence. The Canadian Incidence Study of Reported Child Abuse and Neglect (CIS) is the only resource that depicted the characteristics of child maltreatment investigations conducted by child welfare agencies across Canada (Trocmé \& Wolfe, 2001). Based on Lavergne, Dufour and Trocmè's analysis of the CIS-2003 data (2008), Asian Canadian children's report rate of sexual abuse incidence is disproportionally low compared to Caucasian children and other visible minorities (e.g., Aboriginal) in Canada. Asian Americans also have a lower reported child maltreatment rate in comparison to other minority groups in America. (Fuhua \& Qin, 2009; Futa, Hsu, \& Hansen, 2001; Sue, Sue, Sue, \& Takeuchi, 1995). Therefore, it is possible that abuse cases involving Asian children are less likely to surface in North America (Fuhua \& Qin, 2009). As shown in Figure 1, the report of sexual abuse for East Asian immigrant children can be hindered in two ways. First, East Asian children are unlikely to spontaneously disclose the abuse to their parents. Second, East Asian parents may feel shameful to report the case to police thus remaining silent, and/or possibly minimizing the seriousness of the allegations.

In Confucian philosophy, maintaining harmony is an overriding goal that one should pursue. Particularly, individuals should cultivate a pro-social character in that one would place considerable weight on others' wellbeing instead of one's own benefits (Yao, 2000). Therefore, self-absorbedness or self-centeredness will disturb the harmonious relationship and result in chaos and conflicts. An instance of abuse can be considered a personal occurrence that consists 
of details pertaining to negative feelings and emotions. Such self-oriented information is less likely to be remembered for East Asians because group harmony is expected to outweigh personal needs in East Asian culture (Markus \& Kitayama, 1991; Yao, 2000). The essence of cultivating a pro-social character is self-scrutiny. In particular, individuals need to attribute the cause of failure to their own character. Individuals should also be circumspect and conduct selfexamination frequently in order to preserve good virtues and improve one's self in sustaining a harmonious society (Yao, 2000). Thus, East Asian children who are victims of child sexual abuse may blame themselves for the abuse and experience tremendous guilt and shame. Moreover, the majority of the perpetrators involved in child sexual abuse in Canada are the child's relatives or have connections with the child's family (Connolly, Chong, Coburn, \& Lutgens, 2015). Taken together, child immigrants may suppress their memory of the abuse and be reluctant to disclose the abuse in order to prevent condemnation by parents and, thus, sustain a peaceful family environment.

Some child victims may overcome these barriers and actually report the abuse to their family. However, in these cases, their parents may be hesitant to present the case to authorities as East Asian parents may hold concern that such a negative incident can ruin the family and the victim's reputation and damage relationships with other community members (Futa et al., 2001). Specifically, sexual abuse can be perceived as shameful by East Asian families (Futa et al., 2001). Cohen, Hoshino-Browne, and Leung (2007) discussed the difference between Asian Americans and European Americans in terms of how they interpret emotions. Specifically, there are two types of emotional projection: egocentric projection and relational projection. Cohen et al. (2007) stated that European Americans tend to engage in egocentric projection in their emotion understanding, in which they perceive others' emotions on the basis of their own 
emotions. For example, a person who feels sad will also perceive others as sad. However, Asian Americans interpret others' feelings towards themselves based on their beliefs of associated pairs of emotions (i.e., shame and contempt, anger and fear, sadness and sympathy). In other words, for those who employ relational projection in interpreting others' emotions, how they feel about the self can implicate how others see them. For example, a person who is angry will perceive others to be fearful; a person who is sad will expect others to express sympathy.

Therefore, if a dad feels shameful that his daughter was abused, then he would believe that others would look at their family with contempt. Due to the paramount importance of maintaining a positive self in the social context in collectivistic cultures (Markus \& Kiytama, 1991), being perceived with contempt is unacceptable for many East Asian families. As a result, they may simply keep the abuse within the family and prevent the child receiving professional and legal support (Brazelton, 2015; Kenny \& McEachern, 2000). According to Fuhua and Qin (2009), East Asian families are more resistant to disclose family issues and receive help from outsiders due to the emphasis of family cohesion. This in turn may result in more stress and more internalized psychological problems for children from collectivistic cultures. Given that the family plays a significant role in the path of disclosure of sexual abuse, it is important for child protection practitioners (e.g., social workers and forensic investigators) to be aware of the impact of family dynamics in a sexual abuse case, understand the significance of their role as outsiders, and employ cultural sensitive procedures during investigations. 


\section{Language Differences Which May Affect the Prosecution of Child Sexual Abuse}

Episodic memory is defined as memory of a past event from a particular time and place

(Tulving, 1984). The time component is of essence in forming such memory. However, the ability to describe an episode of a past event does not simply involve the retrieval of memories, but also communicating those memories in linguistic terms (Eisenberg, 1985). Children develop a sense of time continually until they are about 9 years old, and their linguistic expression of time follows a predictable pattern. For example, Friedman (1978) found that at age 4, children could describe the sequence of a day's activities. Children tend to use yesterday to represent any time in the past and tomorrow for any day not today Harner (1982), until they master both around age 5 (Nelson \& Fivush, 2004). At age 7, children begin to understand the concept of larger temporal scales such as days of week, months, and seasons in order (Friedman, 1978). Children's ability to provide temporal information regarding an allegation serves many purposes. First, they provide the defendant with opportunity to challenge with an alibi that counter the alleged time reference. Second, children's ability to provide temporal details may serve as an indicator as to their credibility as witnesses (State vs. Taylor, 2005). As children may have difficulties providing an absolute time reference, their judgement about relative time reference with respect to a landmark event, such as a birthday or a holiday, may also be questioned (McWilliams, Lyon, \& Quas, 2016). For example, children may be asked whether the allegation happened "before or after" their birthday. However, it should be cautioned that many landmark events themselves are recurring in nature, thus children's understanding of "before or after" cannot be interpreted precisely (McWilliams et al., 2016). Taking into consideration that children's capacity in providing temporal references is limited, linguistic cues such as that is perceived as facilitating may not serve the right purpose as they can be easily misinterpreted. 
In order to convey the time aspect in describing an episodic memory, native English speaking children need to grasp the various linguistic structures of several tenses: the simple past, present, and future, present perfect and past perfect tenses (already, last week, and so on (Harner, 1982). Children typically learn past tense through a three-phase acquisition process in which they first learn by rote, by general rules, and finally exceptions to those rules (Rumelhart \& McClelland (1986). It is not until middle childhood that they fully master the various linguistic structures of time distinctions (Harner, 1982). Thus, in English, children's ability to recall details of a particular event in the past is heavily dependent on their temporal knowledge and respective linguistic abilities to represent such knowledge.

Contrary to English, Chinese (Mandarin) is a language without tense morphology; in other words, temporal reference in Chinese is usually not determined by any systematic formation of characters or words (see Lin, 2003 for a full review of temporal reference in the Chinese language). A tense-less sentence in Chinese can be interpreted in many ways based on the context of a conversation. However, a time reference can be established with the addition of time adverbs and aspectual markers (grammatical particles added to a sentence that provide additional temporal information regarding a situation. For example, le is an optional particle that usually follows a verb. "I go [le] to school" would indicate a simple past action - I went to school; Another grammatical particle zai could be added to provide a progressive aspect (i.e., -ing) to an action or event "I [zai] go to school" - "I'm going to school”) (e.g., Klein, Li, \& Hendriks, 2000; Lin, 2003). Despite having these grammatical forms as time indicators, they are not mandatory components of a complete Chinese sentence nor are they always used when describing a past event or action. For example, "I go to school" in Chinese has no time reference but contains all the necessary components of a complete sentence structure. In evaluating children's recall of a 
recurring experience, indicators of episodic information include the use of labels in establishing a clear instance-specific detail (e.g., "I cried the first time I was at the dentist" would indicate a specific dentist visit), as well as the grammatical tense of children's report (e.g., "I went to school" would indicate a time in the past). Thus, the non-explicit and often ambiguous indication of time in a typical Chinese conversation may create additional challenges in the questioning of children about past experiences in a forensic context.

As many previous studies of children's memory of a repeated event have been conducted on samples of children whose first language is English, researchers have relied on the labels and the English grammatical tenses to determine the episodic (specific details from a particular event) and generic (what usually happens) features of their report. Cross-cultural research has shown that Euro-American adult participants have a greater tendency to provide more one-time or specific details spontaneously about their life experience than their Mandarin-speaking (Wang, 2006b). Taking into consideration the unique aspects of the Chinese language, challenges may arise when Mandarin-speaking children become involved in the forensic process as alleged victims of sexual abuse. Moreover, as shown in Figure 1, the language style may directly influence children's memory style, as a result, they may be at a disadvantage in court because the law requires Western-style descriptions of individual events, a task that even Western children find difficult (Roberts \& Powell, 2001). In other words, it could be falsely assumed that a Chinese immigrant child cannot recall specific details of one particular event when, in fact, they are simply doing so using Chinese language conventions rather than English conventions (e.g., Han et al., 1998). 


\section{Summary and Conclusions}

Given Canada's multicultural approach in establishing a diverse society, it is important to understand how East Asian immigrants perceive and construct information differently than North Americans, and what steps are needed in conducting investigative interviews with immigrants in the Canadian legal system.

We have argued that there are several cultural influences on East Asian child victims of abuse that make it less likely that they will disclose abuse, or be believed and supported if they do. These factors relate mostly to Confucian values of respect for the family. Disclosing abuse could be considered as bringing shame and dishonour to the family and a child's internal beliefs about family may prevent her/him from disclosing. Research has also shown that recantation of alleged abuse is more common when the alleged victim is not supported by their maternal figure (Malloy \& Lyon, 2006; Malloy, Lyon, \& Quas, 2007).

Even if East Asian children disclose their abuse, the requirements of Western legal systems make it hard for victims to provide the information needed for prosecution. In a typical case involving allegations of child sexual abuse, the Canadian legal system places a high demand on the child to recall each individual instance of the abuse with enough precision to obtain sufficient corroborating evidence in order to make a conviction (Roberts \& Powell, 2001). In the absence of the corroborating evidence, the child victim's testimony may not be considered convincing enough to convict the perpetrator (e.g., R. v. B. (G.), 1990). Typically, investigators need detailed accounts of separate incidents, including the time, place, and other details of single incidents. This is a very difficult task for Western children because, even though they recall accurately what they have experienced, they are confused between different incidents (Roberts \& Powell, 2001). East Asian children are further prejudiced because the Chinese language does not 
lend itself to descriptions of individual and self-focused events. East Asian children may be able to describe their abuse generically (e.g., "He touches me down there"), but generic reports are considered to be less credible than detailed descriptions of individual events (Herlihy, Jobson, \& Turner, 2012) and are harder to prosecute. Therefore, the specificity of child victims' autobiographical recollections of the alleged abuse is positively associated in the legal system with their perceived competence in providing valid testimony. As noted above, the findings from the overall literature have suggested that East Asians tend to recall fewer details in their memory recollections than Westerners (Alea \& Wang, 2015).

As Figure 1 shows, the consequences for East Asian immigrant youth who allege that they are victims of abuse (or are suspected victims) are serious. Asian children face an uphill battle to see justice in sexual abuse cases processed through North American courts. Thus, a significant portion of immigrant children may not see their abusers punished. However, an even worse consequence could be the targeting of East Asian children as potential victims of abuse. If prosecution of child sexual abuse of East Asian child victims is rare, perpetrators of abuse may choose to 'groom' this population given the low chance of prosecution.

It is important that legal and child welfare professionals are made aware of how cultural differences can have serious impacts on criminal investigations. A good first step would be to disseminate knowledge about the unique characteristics that East Asian children bring with them when they immigrate. Consultation with Mandarin speakers from Mandarin-speaking regions of East Asia would also be helpful when children's allegations are ambiguous. For example, it may be ambiguous whether the child alleges that abuse has happened once or multiple times. A Mandarin translator can advise an interviewer about when and how to clarify this with the child. 
Knowledge about the cultural values of East Asian families might also be helpful when there are merely suspicions of abuse, or when a child has recanted. Bronfenbrenner's family ecology model (Bronfenbrenner, 1977) clarifies the many direct and indirect influences that can affect children's behaviour. A child may not fully disclose the abuse if, in their culture, it would bring shame on a family; a child may recant if the mother is unsupportive; a child may not disclose abuse for fear that they will be labeled as homosexual. All these things are influences from the child's cultural experiences and can affect what they say in an interview. Interviewers can use this knowledge as they progress through the case.

It is important to ensure that Mandarin-speaking East Asians are employed as investigative interviewers. An interviewer who has experience of Asian and Western cultures may be more sophisticated at interpreting children's narratives and behaviour, as well as the behaviour of family members. These recommendations are easy to implement and do not impose any financial hardship or difficulty to police services in Canada. We hope that this paper will expose the potential dangers when interviewing children from a different culture. All children are inherently disadvantaged in Western legal systems because they may be asked to do tasks that are difficult even for adults. The cultural norms and values of East Asian immigrants may make justice particularly unlikely for child victims of abuse. Language norms and vocabulary may also provide some barriers to effective prosecution and we have focused in particular on the Mandarin language. Knowledge and consideration of these values may improve the safety and mental health of unfortunate victims; children who should be protected. 


\section{References}

Alea, N., \& Wang, Q. (2015). Going global: the functions of autobiographical memory in cultural context. Memory (Hove, England), 23(1), 1. doi:10.1080/09658211.2014.972416

Brazelton, J. F. (2015). The Secret Storm: Exploring the Disclosure Process of African American Women Survivors of Child Sexual Abuse Across the Life Course. Traumatology. doi:10.1037/trm0000047

Brubacher, S.P., Bala, N.C., Roberts, K., \& Price, H. (2016). Investigative Interviewing of Witnesses and Victims in Canada (pp. 245-255). In D. Walsh. G.E. Oxburgh, A. Redlich, \& T. Myklebust, (Eds.). International Developments and Practices in Investigative Interviewing and Interrogation, Volume I. Routledge, UK.

Brubacher, S. P., Powell, M. B., \& Roberts, K. P. (2014). Recommendations for interviewing children about repeated experiences. Psychology, Public Policy, And Law, 20(3), 325335. doi:10.1037/law0000011

Brubacher, S. P., Roberts, K. P., \& Powell, M. (2012). Retrieval of Episodic Versus Generic Information: Does the Order of Recall Affect the Amount and Accuracy of Details Reported by Children About Repeated Events? Developmental Psychology, 48(1), 111122. doi: $10.1037 / \mathrm{a} 0025864$

Bronfenbrenner, U. (1977). Toward an experimental ecology of human development. American Psychologist, 32(7), 513-531. doi:10.1037/0003-066X.32.7.513

Cohen, D., Hoshino-Browne, E., \& Leung, A. K.-y. (2007). Culture and the Structure of Personal Experience: Insider and Outsider Phenomenologies of the Self and Social World. In M. P. Wanna (Ed.), Advances in Experimental Social Psychology (Vol. 39, pp. 41). San Diego, CA Elsevier. 
Connolly, D. A., Chong, K., Coburn, P. I., \& Lutgens, D. (2015). Factors Associated with Delays of Days to Decades to Criminal Prosecutions of Child Sexual Abuse. Behavioral Sciences \& the Law, 33(4), 546-560. doi:10.1002/bsl.2185

Eisenberg, A. R. (1985). Learning to describe past experiences in conversation*. Discourse Processes, 8(2), 177-204.

Friedman, W. J. (1978). Development of time concepts in children. Advances in child development and behavior, 12, 267-298.

Fuhua, Z., \& Qin, G. (2009). Child Maltreatment Among Asian Americans. Child Maltreatment, 14(2), 207-224. doi:10.1177/1077559508326286

Futa, K. T., Hsu, E., \& Hansen, D. J. (2001). Child Sexual Abuse in Asian American Families: An Examination of Cultural Factors That Influence Prevalence, Identification, and Treatment. Clinical Psychology: Science and Practice, 8(2), 189-209. doi:10.1093/clipsy.8.2.189

Gudykunst, W. B., \& et al. (1996). The Influence of Cultural Individualism- Collectivism, Self Construals, and Individual Values on Communication Styles across Cultures. Human Communication Research, 22(4), 510-543.

Han, J. J., Leichtman, M. D., \& Wang, Q. (1998). Autobiographical memory in Korean, Chinese, and American children. Developmental Psychology, 34, 701-713.

Harner, L. (1982). Talking about the past and the future. The developmental psychology of time, 141-169.

Herlihy, J., Jobson, L., \& Turner, S. (2012). Just Tell Us What Happened to You: Autobiographical Memory and Seeking Asylum. Applied Cognitive Psychology, 26(5), 661-676. doi:10.1002/acp.2852 
Hudson, J. A., Fivush, R., \& Kuebli, J. (1992). Scripts and episodes: The development of event memory. Applied Cognitive Psychology, 6(6), 483-505. doi:10.1002/acp.2350060604

Hudson, J., \& Nelson, K. (1986). Repeated encounters of a similar kind: Effects of familiarity on children's autobiographic memory. Cognitive Development, 1(3), 253-271. doi:10.1016/S0885-2014(86)80004-1

Kelly, A. G. (1991). The psychology of personal constructs. London ; New York: London ; New York : Routledge in association with the Centre for Personal Construct Psychology.

Kenny, M. C., \& McEachern, A. G. (2000). Racial, ethnic, and cultural factors of childhood sexual abuse: A selected review of the literature. Clinical Psychology Review, 20(7), 905922. doi:10.1016/S0272-7358(99)00022-7

Klein, W., Li, P., \& Hendriks, H. (2000). Aspect and assertion in Mandarin Chinese. Natural Language \& Linguistic Theory, 18(4), 723-770.

Kulkofsky, S., Wang, Q., \& Hou, Y. (2010). Why I remember that: The influence of contextual factors on beliefs about everyday memory. Memory \& Cognition, 38(4), 461-473.

Lamb, M. E., Orbach, Y., Hershkowitz, I., Esplin, P. W., \& Horowitz, D. (2007). A structured forensic interview protocol improves the quality and informativeness of investigative interviews with children: A review of research using the NICHD Investigative Interview Protocol. Child abuse \& neglect, 31(11), 1201-1231.

Lavergne, C., Dufour, S., Trocmé, N., \& Larrivée, M.-C. (2008). Visible Minority, Aboriginal and Caucasians Children investigated by Canadian Child protective services. Child Welfare, 87(2), 59-76.

Lin, J.-w. (2003). Temporal Reference in Mandarin Chinese. Journal of East Asian Linguistics, 12(3), 259-311. doi:10.1023/a:1023665301095 
Ma, L.-C., \& Smith, K. (1992). Social correlates of Confucian ethics in Taiwan. Journal of Social Psychology, 132(5), 655.

Malloy, L. C., \& Lyon, T. D. (2006). Caregiver Support and Child Sexual Abuse: Why Does It Matter? Journal of Child Sexual Abuse, 15(4), 97-103. doi:10.1300/J070v15n04_06

Malloy, L. C., Lyon, T. D., \& Quas, J. A. (2007). Filial Dependency and Recantation of Child Sexual Abuse Allegations. Journal of the American Academy of Child \& Adolescent Psychiatry, 46(2), 162-170. doi:10.1097/01.chi.0000246067.77953.f7

Markus, H. R., \& Kitayama, S. (1991). Culture and the Self: Implications for Cognition, Emotion, and Motivation. Psychological Review, 98(2), 224-253.

McWilliams, K., Lyon, T. D., \& Quas, J. A. (2016). Maltreated Children's Ability to Make Temporal Judgments Using a Recurring Landmark Event. Journal of interpersonal violence, 0886260516645812.

Nelson, K., \& Fivush, R. (2004). The emergence of autobiographical memory: a social cultural developmental theory. Psychological review, 111(2), 486.

Peterson, C., Wang, Q., \& Hou, Y. (2009). When I Was Little: Childhood Recollections in Chinese and European Canadian Grade School Children. Child Development, 80(2), 506518. doi:10.1111/j.1467-8624.2009.01275.x

Pipe, M.-E., Orbach, Y., Lamb, M. E., Abbott, C. B., \& Stewart, H. (2013). Do cases outcomes change when investigative interviewing practices change? Psychology, Public Policy, and Law, 19(2), 179-190. doi:10.1037/a0030312

Powell, M. B., \& Thomson, D. M. (1996). Children's memory of an occurrence of a repeated event: Effects of age, repetition, and retention interval across three question types. Child Development, 67(5), 1988-2004. doi:10.2307/1131605 
R. v. B.(G.), (1990) 2 S.C.R. 3.

Roberts, K.P., Brubacher, S.P., Price, H.L., \& Powell, M.B. (2011). Practice narratives (pp.129145). In Lamb, M.E., La Rooy, D., Katz, C., \& Malloy, L. Children's testimony: A Handbook of psychological research and forensic practice. Wiley-Blackwell

Roberts, K. P., \& Cameron, S. C. (2015). Observations from Canadian practitioners about the investigation and prosecution of crimes involving child and adult witnesses. Journal Of Forensic Psychology Practice, 15(1), 33-57. doi:10.1080/15228932.2015.997611

Roberts, K. P., \& Powell, M. B. (2001). Describing Individual Incidents of Sexual Abuse: A Review of Research on the Effects of Multiple Sources of Information on Children's Reports. Child Abuse \& Neglect: The International Journal, 25(12), 1643-1659.

Roberts, K. P., \& Powell, M. B. (2006). The consistency of false suggestions moderates children's reports of a single instance of a repeated event: Predicting increases and decreases in suggestibility. Journal of Experimental Child Psychology, 94(1), 68-89. doi:10.1016/j.jecp.2005.12.003

Roberts, K. P., \& Powell, M. B. (2007). The roles of prior experience and the timing of misinformation presentation on young children's event memories. Child Development, 78(4), 1137-1152. doi:10.1111/j.1467-8624.2007.01057.x

Rischke, A. E., Roberts, K. P., \& Price, H. L. (2011). Using spaced learning principles to translate knowledge into behavior: Evidence from investigative interviews of alleged child abuse victims. Journal Of Police And Criminal Psychology, 26(1), 58-67. doi:10.1007/s 11896-010-9073-8 
Rumelhart, D. E., \& McClelland, J. L. (1986). On learning the past tenses of English verbs. In E. R. David, L. M. James, \& C. P. R. Group (Eds.), Parallel distributed processing: explorations in the microstructure of cognition, vol. 2 (pp. 216-271): MIT Press.

State v. Taylor, 116360 (2005).

Sue, S., Sue, D. W., Sue, L., \& Takeuchi, D. T. (1995). Psychopathology Among Asian Americans: A Model Minority? Cultural Diversity and Mental Health, 1(1), 39-51. doi:10.1037/1099-9809.1.1.39

Thierry, K. L., \& Spence, M. J. (2002). Source-monitoring training facilitates preschoolers' eyewitness memory performance. Developmental Psychology, 38(3), 428-437. doi:10.1037/0012-1649.38.3.428

Trocmé, N., Fallon, B., MacLaurin, B., Sinha, V., Black, T., Fast, E., et al. (2010). CIS-2008: Executive Summary. In Public Health Agency of Canada (Ed.), Canadian Incidence Study of Reported Child Abuse and Neglect-2008: Major findings (pp. 1-7). Ottawa, ON: Minister of Public Works and Government Services Canada.

Trocmé, N., Wolfe, D. (2001). Canadian Incidence Study of Reported Child Abuse and Neglect. Retrieved from http://www.phac-aspc.gc.ca/publicat/cissr-ecirc/index-eng.php Tulving, E. (1984). Precis of elements of episodic memory. Behavioral and Brain Sciences, 7(02), 223-238.

Wang, Q. (2001). Culture Effects on Adults; Earliest Childhood Recollection and SelfDescription: Implications for the Relation Between Memory and the Self. Journal of Personality and Social Psychology, 81(2), 220-233. doi:10.1037/0022-3514.81.2.220

Wang, Q. (2006a). Culture and the Development of Self-Knowledge. Current Directions in Psychological Science, 15(4), 182-187. 
Wang, Q. (2006b). Earliest recollections of self and others in European American and Taiwanese young adults. Psychological Science, 17(8), 708-714.

Wang, Q. (2007). Remember when you got the big, big bulldozer? mother- child reminiscing over time and across cultures. Social Cognition, 25(4), 455-471.

Wang, Q. (2009). Once upon a time: Explaining cultural differences in episodic specificity. Social and Personality Psychology Compass, 3(4), 413-432.

Wang, Q., \& Conway, M. A. (2004). The Stories We Keep: Autobiographical Memory in American and Chinese Middle- Aged Adults. Journal of Personality, 72(5), 911-938. doi:10.1111/j.0022-3506.2004.00285.x

Wang, Q., \& Leichtman, M. D. (2000). Same Beginnings, Different Stories: A Comparison of American and Chinese Children's Narratives. Child Development, 71(5), 1329-1346.

Wang, Q., Leichtman, M. D., \& Davies, K. I. (2000). Sharing memories and telling stories:

American and Chinese mothers and their 3- year- olds. Memory (Hove, England), 8(3), 159.

Wang, Q., \& Ross, M. (2005). What we remember and what we tell: The effects of culture and self-priming on memory representations and narratives. Memory, 13, 594-606.

Yao, X. (2000). An introduction to Confucianism: New York : Cambridge University Press, 2000. 
Figure 1. The mechanisms through which East Asian immigrant children may be disadvantaged in the Canadian legal system. 